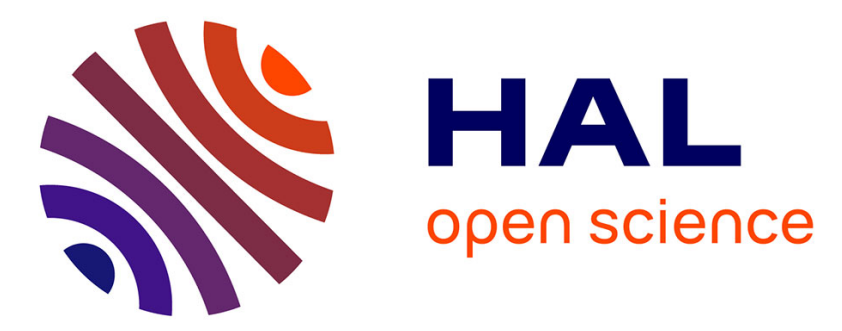

\title{
3D micro structural analysis of human cortical bone in paired femoral diaphysis, femoral neck and radial diaphysis
}

Rémy Gauthier, Max Langer, Hélène Follet, Cécile Olivier, Pierre-Jean Gouttenoire, Lukas Helfen, Frédéric Rongieras, David Mitton, Françoise

Peyrin

\section{To cite this version:}

Rémy Gauthier, Max Langer, Hélène Follet, Cécile Olivier, Pierre-Jean Gouttenoire, et al.. 3D micro structural analysis of human cortical bone in paired femoral diaphysis, femoral neck and radial diaphysis. Journal of Structural Biology, 2018, 204 (2), pp.182-190. 10.1016/j.jsb.2018.08.006 . hal01858412

\section{HAL Id: hal-01858412 https://hal.science/hal-01858412}

Submitted on 20 Aug 2018

HAL is a multi-disciplinary open access archive for the deposit and dissemination of scientific research documents, whether they are published or not. The documents may come from teaching and research institutions in France or abroad, or from public or private research centers.
L'archive ouverte pluridisciplinaire HAL, est destinée au dépôt et à la diffusion de documents scientifiques de niveau recherche, publiés ou non, émanant des établissements d'enseignement et de recherche français ou étrangers, des laboratoires publics ou privés. 
3D micro structural analysis of human cortical bone in paired femoral diaphysis, femoral neck and radial diaphysis

Rémy Gauthier ${ }^{1,2}$, Max Langer ${ }^{2}$, Hélène Follet ${ }^{3}$, Cécile Olivier ${ }^{2,5}$, Pierre-Jean Gouttenoire ${ }^{2,5}$, Lukas Helfen $^{5}$, Frédéric Rongiéras ${ }^{1,4}$, David Mitton ${ }^{1}$ and Françoise Peyrin ${ }^{2,5}{ }^{*}$

1 Univ Lyon, Université Claude Bernard Lyon 1, IFSTTAR, LBMC UMR_T9406, F69622, Lyon, France;

2 Univ Lyon, CNRS UMR 5220, Inserm U1206, INSA Lyon, Université Claude Bernard Lyon 1, Creatis, F69621 Villeurbanne Cedex, France;

3 Univ Lyon, Université Claude Bernard Lyon 1, INSERM, LYOS UMR1033, F69008, Lyon, France ;

4 Service Chirurgie Orthopédique et Traumatologie - Hôpital Desgenettes, 69003, Lyon, France;

5 European Synchrotron Radiation Facility, CS 40220, 38043 Grenoble Cedex 9 France;

* Corresponding author: peyrin@esrf.fr, +334 76882335

Abstract: Human bone is known to adapt to its mechanical environment in a living body. Both its architecture and microstructure may differ between weight-bearing and non-weight-bearing bones. The aim of the current study was to analyze in three dimensions, the morphology of the multi-scale porosities on human cortical bone at different locations. Eight paired femoral diaphyses, femoral necks, and radial diaphyses were imaged using Synchrotron Radiation $\mu \mathrm{CT}$ with a $0.7 \mu \mathrm{m}$ isotropic voxel size. The spatial resolution facilitates the investigation of the multiscale porosities of cortical bone, from the osteonal canals system down to the osteocyte lacunar system. Our results showed significant differences in the microstructural properties, regarding both osteonal canals and osteocytes lacunae, between the different anatomical locations. The radius presents significantly lower osteonal canal volume fraction and smaller osteonal canals than the femoral diaphysis or neck. Osteocytes lacunae observed in the radius are significantly different in shape than in the femur, and lacunar density is higher in the femoral neck. These results show that the radius, a nonweight-bearing bone, is significantly different in terms of its microstructure from a weight-bearing bone such as the femur. This implies that the cortical bone properties evaluated on the femoral diaphysis, the main location studied within the literature, cannot be generalized to other anatomical locations. 


\section{Introduction}

Bone micro-architecture has been largely studied among several years in order to better understand its growth process or its mechanical properties. This hierarchical organization is the locus of a biological activity that will specify the overall quality of the tissue (Busse et al., 2010; Currey and Shahar, 2013; Gourion-Arsiquaud et al., 2009; Hannah et al., 2010; Nalla et al., 2006; Pfeiffer et al., 2006; Seeman and Delmas, 2006; van Oers et al., 2008; Varga et al., 2014).

On the microscopic scale, cortical bone main porosity is related to the osteonal canals forming a network hosting blood vessels and nerves. The osteonal canals in humans are approximately $50-100$ $\mu \mathrm{m}$ in diameter and a few millimeters in length (Jowsey, 1966). Osteonal canals play a major role in the bone remodeling process due to the passage of blood and nutriments. The bone matrix also exhibits a porous network on a finer scale. This system is the lacuno-canalicular network (LCN) that hosts the osteocytes network. The osteocytes, which are the most numerous cells present in bone material, are hypothesized to play a key mechanosensor role in the adaptive capacity of bone in its particular mechanical environment (Bonewald, 2011; Busse et al., 2010). They are included in osteocyte lacunae that are roughly ellipsoidal (Marotti, 1979) and are connected by small canals, canaliculi, containing the processes of the osteocytes.

In addition with these porosities, bone also includes defects that are caused by different type of damages occurring throughout the lifetime of the tissue (Vashishth, 2007). The main type of damage is linear micro-cracks, and the second type is the diffuse micro-damage, which will not be discussed here. The planar micro-cracks, defects which can span hundreds of $\mu \mathrm{m}$ in length and a gap of about 1 $\mu \mathrm{m}$, are the result of fatigue of the bone material due to external loading. The presence of such damages within cortical bone may be associated to a weakening of the tissue resulting in an increased fracture risk (Burr, 2001; Burr et al., 1997). This is why the analysis of micro-cracks appears to be relevant. These micro-damages are also assumed to be related to the bone remodeling process. The detection of such defects by the osteocytes may act as a signal for remodeling (Burr et al., 1985; Lee et al., 2002).

The morphology of the osteonal canals has largely been investigated using $2 \mathrm{D}$ techniques such as histology or micro-radiography (Bell et al., 1999; Jowsey et al., 1953). Both of these techniques facilitate the observation of canals but only on sections of bone. More recently, the three-dimensional vascular network has been largely studied in cortical bone mostly using micro-computed tomography as it allows the investigation on large volumes (Bala et al., 2016; Bousson et al., 2004; Chappard et al., 2006; Cooper et al., 2007). It seems important to investigate such a network in 3D as it has been shown that the orientation of these canals may be associated to their mechanical environment (Hennig et al., 2015; Heřt et al., 1994). Studies on this vascular system has shown that its 3D organization may 
be determinant regarding bone mechanical properties and remodelling process (Bala et al., 2016; Perilli et al., 2015; Zebaze et al., 2010).

The observation of micro-cracks and osteocytes is usually conducted using imaging methods such as Scanning Electron Microscopy (SEM) (Granke et al., 2016; Milovanovic et al., 2015), visible light microscopy (Wang et al., 2005), and confocal microscopy (Lai et al., 2015; Verbruggen et al., 2012) or UV light microscopy (Follet et al., 2013). However, most of these different techniques only provide 2D images of micro-cracks and the LCN. Schneider et al. (2011) used a SEM coupled with focused ion beam milling to investigate a three-dimensional (3D) region containing lacunae (Schneider et al., 2011). Although this technique can provide high-resolution 3D renderings of osteocyte lacunae, the size of the region of interest (ROI) remains limited to one or two lacunae due to the extensive scanning time. $\mu \mathrm{CT}$ has also been used to investigate the morphometric properties of osteocyte lacunae within a larger region (van Hove et al., 2009; Vatsa et al., 2008). However, recent studies have shown that the segmentation of osteocyte lacunae from such images might compromise the quantitative analysis because of the need to develop complex algorithms (Betts et al., 2017).

Synchrotron radiation (SR) CT was previously used to image and analyze osteocyte lacunae in human femoral cortical bone (Dong et al., 2014; Hannah et al., 2010). It also facilitates imaging of the LCN (Langer et al., 2012; Pacureanu et al., 2012) and bone micro-cracks (Larrue et al., 2011). The advantage of this technique compared to standard CT in this context is that it can offer a higher signalto-noise ratio, even at higher spatial resolution (Salomé et al., 1999), thus facilitating the segmentation of lacunae and its quantitative analysis. Synchrotron radiation also provides a high flux, allowing a significant decrease of scanning time.

To the authors' knowledge, no data has been produced describing such properties of the vascular system, micro-cracks and lacunae on other anatomical sites beyond the human femoral diaphysis. As bone architecture is dependent of its mechanical environment during life and because bone fracture behavior is related to its microstructure (Zimmermann and Ritchie, 2015), the weight-bearing or nonweight-bearing nature of bone may have an influence on this fracture behavior (Maude et al., 2017; Mikkola et al., 2008; Vico et al., 2000). Here, weight-bearing and non-weight-bearing bones are assumed to correspond to the leg's bones and the arm's bones, respectively. This is nevertheless a simplification as even arm's bones are subjected to some load during life.

Thus, the aim of this study is to quantify in 3D the morphology of the multi-scale porosities on paired human femoral diaphysis femoral neck and radial diaphysis based on SR- $\mu$ CT imaging at the submicrometric scale. 


\section{Materials and methods}

\subsection{Sample description}

Paired femoral diaphyses, femoral necks, and radial diaphyses were collected from 8 female donors (70 \pm 14 y.o., min: 50 y.o., max: 91 y.o.) provided by the Departement Universitaire d'Anatomie Rockefeller (Lyon, France) through the French program on voluntary corpse donation to science. No additional information regarding disease status or medication history was available. Extracted bones were wrapped in gauze soaked with saline to keep them hydrated and then stored at $-20^{\circ} \mathrm{C}$ until sample preparation. Two contiguous rectangular samples were extracted from each bone using a low speed saw with a diamond-coated blade (ISOMET 4000, Buehler, USA). This was done in order to consider the internal variability within the same bone. Samples were extracted from the lateral region of the femoral diaphysis, at nearly $60 \%$ of the diaphysis height $(0 \%=$ distal epiphysis) on each donor. On the femoral neck, the specimens were taken from the inferior region for reasons of cortical availability. On the radius, the samples were extracted at nearly $70 \mathrm{~mm}$ from the proximal epiphysis on the anterior region, which corresponds to the region used in a previous study involving ultrasound guided waves (Vallet et al., 2016). The samples were extracted in the middle between the endosteal and the periosteal surface. A delipidation protocol was applied one week before imaging: the samples were immerged in acetone for 30 minutes, then rinsed with water, and finally dehydrated by successive immersion in $70 \%$ and nearly $100 \%$ ethanol baths for a maximum period of 2 days. Samples of 2.09 $\pm 0.14 \mathrm{~mm}$ in width and $0.99 \pm 0.07 \mathrm{~mm}$ in thickness were extracted. The height was about $12.5 \mathrm{~mm}$ in order to facilitate a proper clamping during the acquisition (Figure 1). 


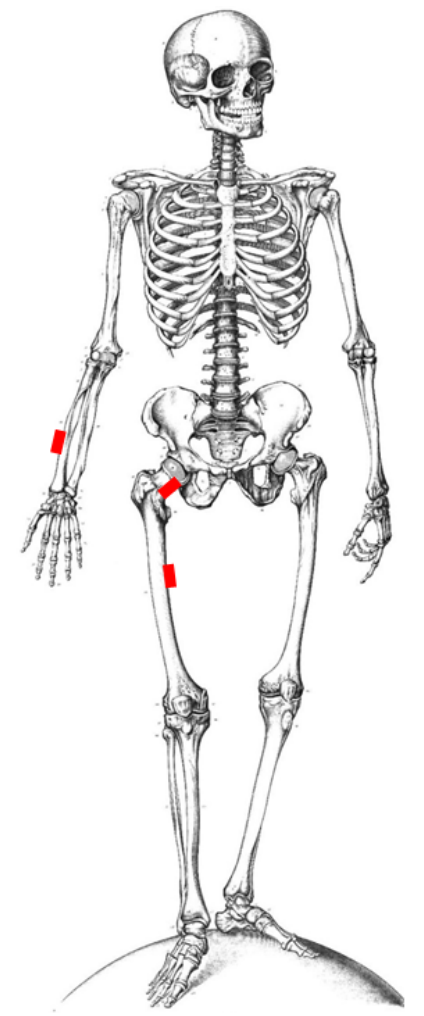

Two contiguous samples Complete VOI

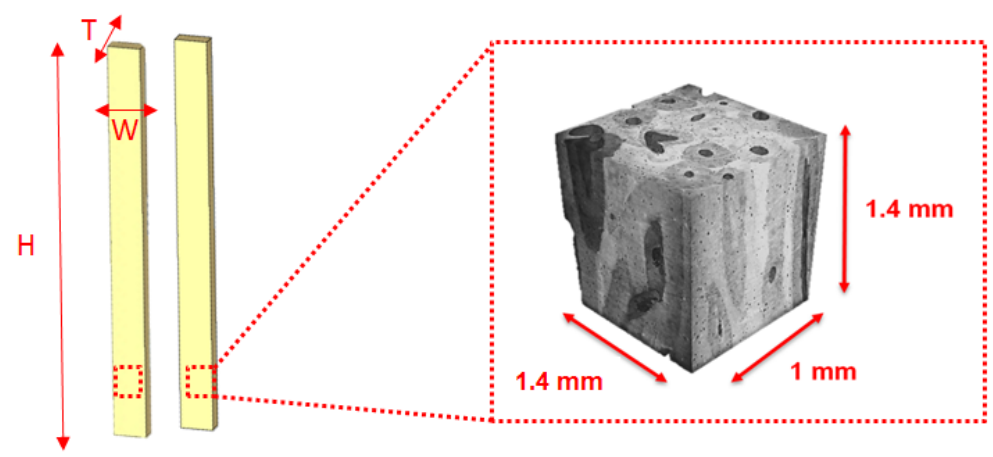

$W=2.09 \pm 0.14 \mathrm{~mm} / \mathrm{T}=0.99 \pm 0.07 \mathrm{~mm} / \mathrm{H}=12.5 \mathrm{~mm}$

Figure 1 Summary of samples preparation from the three paired locations (T: thickness ; W: width ; H: height)

\subsection{Synchrotron radiation micro-computed tomography (SR- $\mu \mathrm{CT})$}

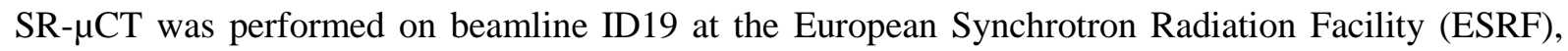
Grenoble, France. We used a "pink beam" filtered undulator radiation with an effective energy of 31 $\mathrm{keV}$. The detector was composed of a scintillator screen, a visible light microscope, and a CCD camera and was set up to yield an effective pixel size of $0.7 \mu \mathrm{m}$. For each sample, 2000 projection images were recorded over a total rotation of $360^{\circ}$, with a counting time of $0.3 \mathrm{~s}$ per projection and a total scan time of 14 minutes. Phase contrast was obtained by placing the detector at $40 \mathrm{~mm}$ from the sample. The images were reconstructed with and without phase retrieval. Phase retrieval was performed using Paganin's method (Paganin et al., 2002), with the $\delta / \beta$-ratio set to 572 . Tomographic reconstructions were performed using a filtered back-projection algorithm yielding 3D images with $2048^{3}$ voxels.

A total of 48 scans were recorded ( 8 female donors, 3 anatomical locations and 2 volumes of interests (VOIs) for each location). Since the field of view (FOV) on the detector was $1.4 \times 1.4 \mathrm{~mm}^{2}$, the samples were not completely included in the FOV for some angles, yielding to local tomography (Paleo and Mirone, 2017). The size of the reconstructed bone volume of interest (VOI) was approximately 1 x 1.4 $\mathrm{x} 1.4 \mathrm{~mm}^{3}$. Because of some motion problem during the acquisition, 5 scans were not exploitable. 


\subsection{D image analysis}

The analyses were performed on the two contiguous samples. The values retained for the further analysis of the investigated parameters were considered as the average between these two samples (Figure 1). Statistical analyses were performed to check for any difference between these two contiguous samples (cf. 2.4).

\subsubsection{Segmentation of canals, lacunae and micro-cracks}

The first step consisted of the segmentation of the different structures of interest: osteonal canals, lacunae, and micro-cracks. To this aim, a bone mask was generated by thresholding using Otsu's method after applying a median filter to remove lacunar and other small porosities. The total bone envelope was obtained as the convex hull of the binarized bone image. Subsequently, the canal mask was obtained as the complement of the bone volume in the bone envelope. Lacunae and micro-cracks were then segmented using hysteresis thresholding limited to within the bone mask. Hysteresis thresholding uses a low and a high threshold value as input parameters. The low value facilitates the selection of voxels that are directly labeled as osteocyte lacunae or micro-cracks. The higher threshold permits the refinement of the segmentation by adding voxels with higher intensity values, but only if they are connected to the previously detected voxels. Due to the local CT acquisition in the current study, the reconstructed attenuation coefficient could be shifted from one sample to another. Therefore, the hysteresis thresholding low and high values were determined manually for each sample. Finally, a binarized volume containing lacunae and micro-cracks was obtained (Figure 2). Bone volume (BV) was calculated by multiplying the inverse of the final binarized VOI with the canals mask. BV was considered as the sum of the BVs measured on the two contiguous samples.

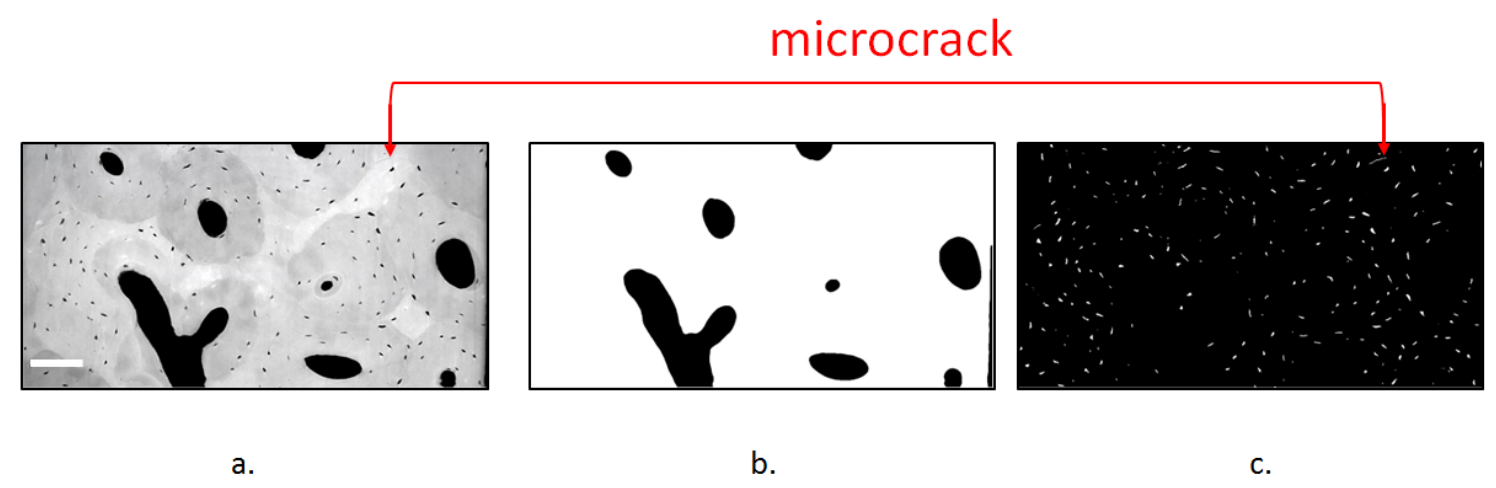

Figure 2 VOI slices from a femoral diaphysis bone sample; a. initial phase contrast image, $b$. canals mask and $c$. final binarized image containing osteocytes and micro-cracks. Notice the micro-cracks pointed by the red arrow. Scale bar: $100 \mu \mathrm{m}$.

\subsubsection{Osteonal canal analysis}

The analysis of the osteonal canals was done using the canal mask image with the automated commercial software (CTAnalyser Software V 1.14.4, Skyscan NV, Kontich, Belgium). On these 
segmented VOIs (Figure 3), the canal volume fraction Ca.V/TV (\%) was evaluated. TV was measured by adding all of the voxels of the analyzed volume. The mean diameter of the canals, Ca.Dm $(\mu \mathrm{m})$, and the standard deviation Ca.Dm.SD $(\mu \mathrm{m})$ corresponding to the heterogeneity of canals' size within a same bone sample were also measured. The analysis of the osteonal canal was realized on the complete scanned regions of the two contiguous samples resulting in a total volume of twice $(1 \mathrm{x} 1.4 \mathrm{x}$ 1.4) $\mathrm{mm}^{3}$ (Figure 1).

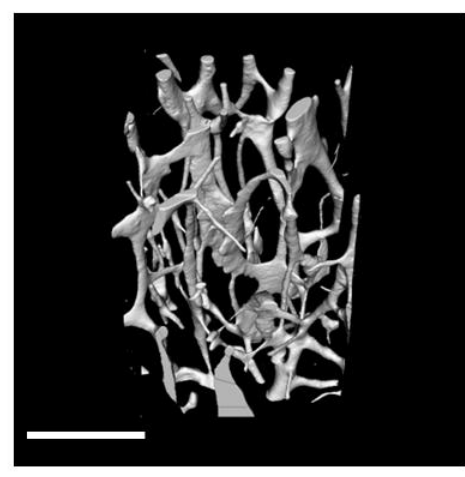

a.

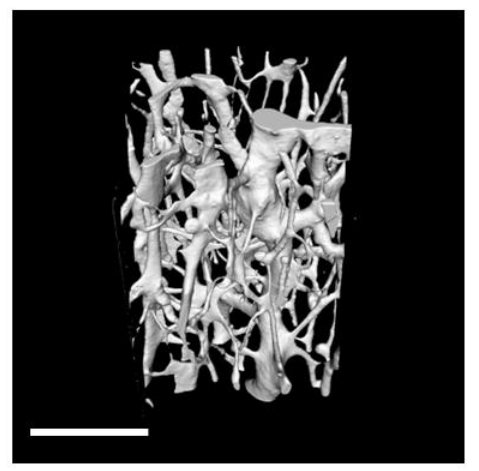

b.

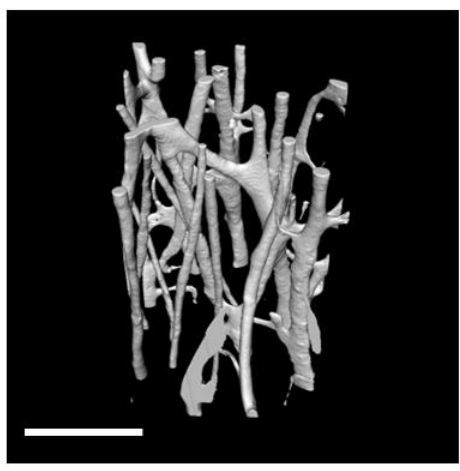

c.

Figure 3 3D Volume rendering of the osteonal canals network segmented on the full VOls at different anatomical sites on the same subject a. femoral diaphysis, b. femoral neck and $c$. radial diaphysis. Scale bars: $500 \mu \mathrm{m}$.

\subsubsection{Morphometric parameters on lacunae and micro-cracks}

Since the detailed analysis of lacunae and micro-cracks is highly time consuming, it was performed with cropped VOIs of $500 \times 500 \times 1000 \mu \mathrm{m}^{3}$. As previously performed, the total volume for the analysis of lacunae and micro-cracks was $2 \times(500 \times 500 \times 1000) \mu \mathrm{m}^{3}$, the lacunar analysis was thus performed over 10.000 lacunae for each samples (cf. table 3).

From the binary volume of lacunae and micro-cracks, morphometric descriptors of each object were calculated using the method proposed by Dong et al. (Dong et al., 2014). The first step was to perform a connected component analysis to label each object (either lacuna or micro-crack). Then, the following parameters were computed on each labeled object (we keep the notations used for lacunae):

- Object Volume (Obj.V): This is the sum of all the voxels within the cell multiplied by the volume of one voxel $\left(0.7 \times 0.7 \times 0.7 \mu \mathrm{m}^{3}\right)$

- Object dimensions (Obj.L1), width (Obj.L2) and depth (Obj.L3) assuming an ellipsoidal shape; L1, L2 and L3 are the three axes of the best fitting ellipsoid, with L1 being the main axis. 
- Object thickness (Obj.Th): This measure is assessed using an automated algorithm assigning the value of the diameter of the maximal fitting sphere within the structure (Martín-Badosa et al., 2003).

- Object surface area (Obj.S), object structure model index (Obj.SMI), and object Euler number (Obj. $\chi$ ): This value is calculated using the intrinsic volumes Obj. $\mathrm{V}_{0}$, Obj. $\mathrm{V}_{1}$, and Obj. $\mathrm{V}_{2}$, which are geometrical invariant used in 3D image processing, by applying the following equations (Schladitz et al., 2006):

$$
\text { Obj.S }=2 \text { Obj. } V_{2}, \quad O b j \cdot \chi=O b j . V_{0},
$$

$$
\text { Obj. SMI }=\frac{12 \pi \text { Obj. } V \text { Obj. } V_{1}}{\text { Obj. } S^{2}}
$$

Where Obj.V represents the object volume. The Euler number is a descriptor of the topological property of the object. It indicates the number of connected components minus the number of tunnels plus the number of cavities (Di Zenzo et al., 1996). The SMI's value ranges between 0 and 4 and defines the global shape of the object: $\mathrm{SMI}=0$ for a pure plate, $\mathrm{SMI}=3$ for a rod, and $\mathrm{SMI}=4$ for a sphere (Hildebrand and Rüegsegger, 1997).

\subsubsection{Separation of osteocytes and micro-cracks}

So far, the segmented structures analyzed as described above can be either lacunae or micro-cracks. Lacunae are denoted by Lc and micro-cracks by $\mu \mathrm{Cr}$. Since these structures are assumed to have quite different shapes, we defined the criteria based on the different descriptors to identify them, similarly to those proposed by Dong et al. (Dong et al., 2014). First, objects with a volume smaller than $82 \mu \mathrm{m}^{3}$ were considered as noise incorrectly classified as porosity and were therefore subsequently removed (Dong et al., 2014). Objects with a volume larger than $10000 \mu \mathrm{m}^{3}$ were also excluded from the lacuna class, considered as either an incorrectly segmented object or crack. Criteria were also applied to some geometrical ratios; objects with Lc.L1/Lc.Th ratio higher than 15 and Lc.L2/Lc.Th ratio higher than 8 were excluded and considered as micro-cracks. Lc.SMI and Lc. $\chi$ were also exploited as exclusion criteria: lacunae were considered as having a SMI higher than 1.6 and an Euler number ranging from 0 to 2. A summary of these criteria is given in Table 1 .

To extract micro-cracks $(\mu \mathrm{Cr})$, we selected cells with a volume higher than $500 \mu^{3}$ to exclude small objects due to noise. To exclude lacunae, we used the opposite criteria as done previously on Obj.L1/Obj.Th and Obj.L2/Obj.Th ratios, since micro-cracks have relatively small thicknesses compared to other objects. Objects with Obj.L1/Obj.L3 ratios lower than 5 and features with ObjL2/Obj.L3 lower than 3 were considered as ring artefacts, since these incorrectly segmented objects had a relatively short ellipsoid axis L3 compared to cracks. Finally we defined the objects with 
SMIs lower than 2.5 to exclude other types of artefacts. A summary of these criteria is given in Table 1.

The Euler number $(\chi)$ and SMI were only used for the separation step; they were not used for any further analysis. Their values are thus not given.

Table 1 Summaries of exclusion criteria for osteocytes lacunae and microcracks

\begin{tabular}{c|c}
\hline Osteocytes lacunae & Microcracks \\
\hline Obj.V $>82 \mu \mathrm{m}^{3}$ & Obj.V $>500 \mu \mathrm{m}^{3}$ \\
\hline Obj.V $<10000 \mu \mathrm{m}^{3}$ & Obj.L1/Obj.Th $>15$ and Obj.L2/Obj.Th $>8$ \\
\hline Obj.L1/Obj.L3<15 and Obj.L2/Obj.L3 $<8$ & Obj.L1/Obj.L3 $>5$ and Obj.L2/Obj.L3 $>2$ \\
Obj.SMI $>1.6$ & Obj.SMI $<2.5$ \\
$0<$ Obj. $\chi<2$ & - \\
\hline
\end{tabular}

\subsubsection{Lacunae and cracks analysis}

After the previously described step, we obtained two distinct binary volumes, including on one hand, the lacunae and on the other hand the micro-cracks. The different geometrical parameters listed above were then recalculated for each of these. Henceforth, as the two different features are investigated separately, lacunae are denoted by Lc and micro-cracks by $\mu \mathrm{Cr}$.

The dimensions of the lacunae were taken as the three axes of the best-fitting ellipsoid, Lc.L1 $(\mu \mathrm{m})$, Lc.L2 $(\mu \mathrm{m})$, and Lc.L3 $(\mu \mathrm{m})$. The mean individual volume and surface, Lc.V $\left(\mu \mathrm{m}^{3}\right)$ and Lc.S $\left(\mu \mathrm{m}^{2}\right)$, respectively, were evaluated. In order to characterize the curvature at the top of the elliptic lacunae, we introduced Lc. $\rho_{1}(\mu \mathrm{m})$ and Lc. $\rho_{2}(\mu \mathrm{m})$ as follows:

$L c \cdot \rho_{1}=\frac{L c . L 2^{2}}{L c . L 1}$ and Lc. $\rho_{2}=\frac{L c \cdot L 3^{2}}{L c . L 1}$

A high Lc. $\rho_{\mathrm{i}}$ is indicative of a less elliptical lacuna; the lower the radii of curvature are, the more discshaped the ellipsoid is, and the higher they are, the more spherical the ellipsoid is. The lacunar volume fraction, Lc.V/BV (\%) was calculated. Finally, the lacunar density, Lc.N/BV $\left(\mathrm{mm}^{-3}\right)$, was measured. The bone volume (BV) was considered to be the voxels that were not in an osteonal canal. Osteocyte lacunae and microcracks were thus considered to be included in BV. In that way, lacunae and microcracks volume fraction or density were assessed considering a volume (BV) in which we might 
find one of these features, whereas in the osteonal canal, we know that we would not observe any lacunae or micro-cracks.

\subsection{Statistical analysis}

In order to use an averaged value for the two contiguous samples instead of two distinct values, the two data sets corresponding to the two contiguous samples were arranged randomly, resulting in 8 groups of 2 samples for each anatomical location. Friedman tests were then performed to check for differences; samples with p-value $<0.05$ were considered as significantly different. This was done to validate that the results obtained from the two contiguous samples can be averaged to give a unique result considering a larger volume being equal to twice the volume of one sample. This also provides information regarding the variability inside a similar anatomical location.

After averaging the two contiguous samples, Friedman tests were performed to investigate whether there are differences between the locations. In the case of the significant results from the Friedman test (p-value $<0.05$ ), we analyzed the differences between anatomical locations by applying the Wilcoxon tests for paired samples. The mean values and interquartile range (IQR) are given in the tables. Statistical analysis was performed using StatView (Abaqus, USA).

Finally, relationships between the parameters of the canals and lacunar system between the different anatomical locations were investigated using Spearman's coefficient. Correlations were considered as significant if $\mathrm{p}$-value $<0.05$.

\section{Results}

Figure 4 presents a 3D rendering of control VOIs for the 3 anatomical locations. No significant correlation with age considering the different investigated structural features was found. 

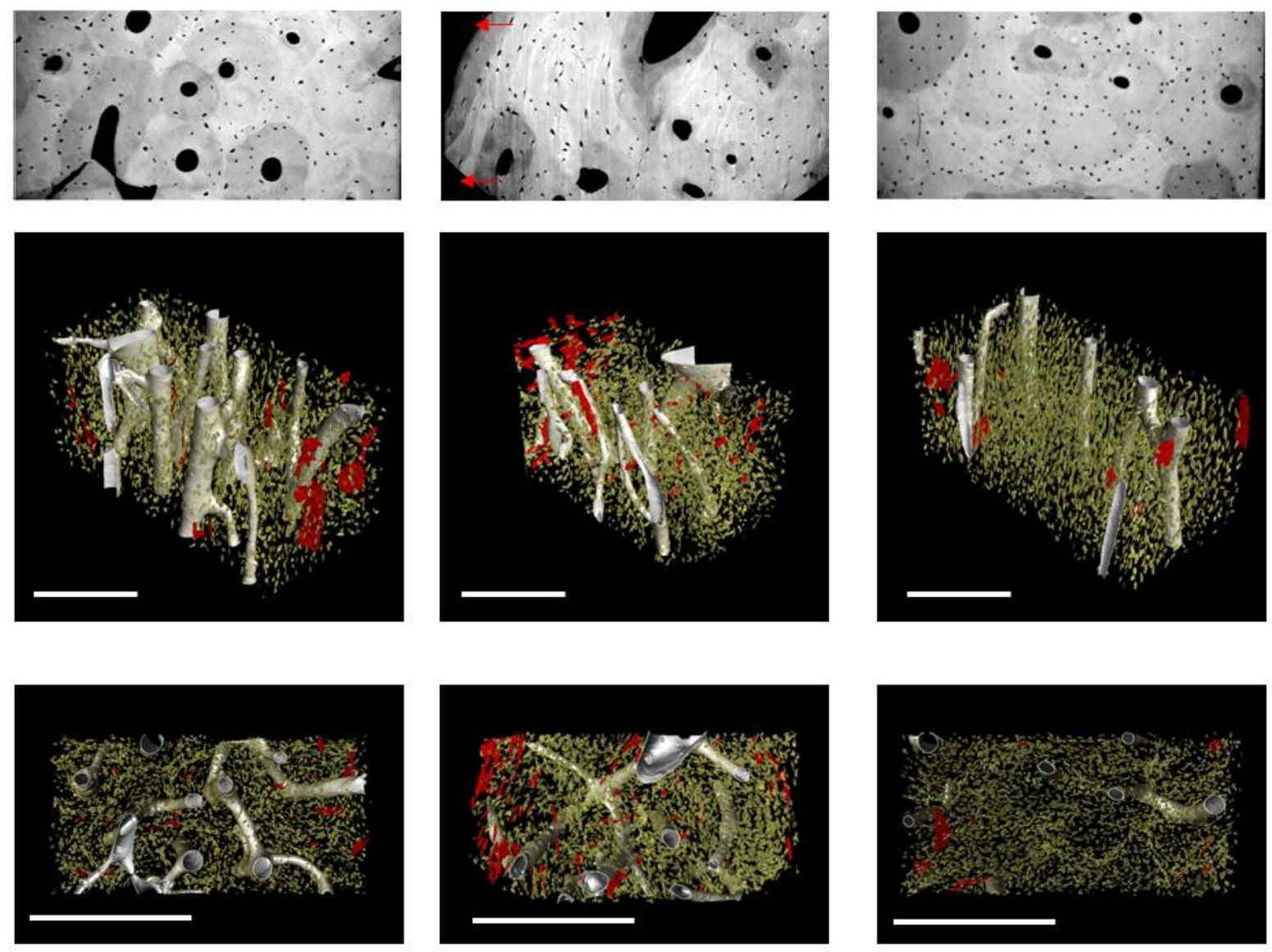

Femoral diaphysis

Femoral neck

Radial diaphysis

Figure 4 VOls of human femoral diaphysis, femoral neck and radial diaphysis in one subject (Woman, 50 y.o.). Top: original phase contrast slice, middle and bottom: 3D volume renderings under two orientations. Lacunae are represented in yellow, and micro-cracks in red.

\subsection{Comparison between contiguous samples.}

A significant difference between the contiguous samples was observed for the SD Ca.Dm measured on the femoral neck. No difference was observed for all other parameters, considering both osteonal canals and osteocytes lacunae. From these results, the authors considered the average of the two samples as the result for each location. This implies that the analyses was performed on twice the volume of one sample, meaning $2 \times(1.4 \times 1.4 \times 1) \mathrm{mm}^{3}$ for the osteonal canals, and $2 \times(500 \times 500 \times$ 1000) $\mu \mathrm{m}^{3}$ for the lacunae and micro-cracks were analysed.

\subsection{Osteonal canals}

Table 2 and Erreur! Source du renvoi introuvable. present the osteonal canal morphometric parameters means and values over the 8 subjects in control VOIs. The radius shows a lower canal volume fraction than the femur. Ca.V/TV is $49 \%$ and $56 \%$ lower in the radius than in the femoral 
diaphysis and femoral neck, respectively. No difference is measured regarding the averaged canals diameter (Ca.Dm) using Wilcoxon test. Friedman statistical test resulted in a significant difference between the canal diameter from the femoral neck and the radius, with canals $27 \%$ smaller in the radius. The standard variation of canal thickness within the tissue was also $47 \%$ higher in the femoral neck and $51 \%$ higher than the femoral diaphysis than in the radius. The femoral neck has a more heterogeneous osteonal canals system.

Table 2 Mean values (IQR) for osteonal canals morphometric parameters measured in the VOIs.

\begin{tabular}{cccc}
\hline $\begin{array}{c}\text { Morphometric } \\
\text { parameters }\end{array}$ & Femoral diaphysis & Femoral neck & Radial diaphysis \\
\hline Ca.V/TV $(\boldsymbol{\%})$ & $8.45(2.80)^{\mathrm{r}^{*}}$ & $9.94(4.40)^{\mathrm{r}^{*}}$ & $4.34(2.46)^{\mathrm{d}^{*} \mathrm{n}^{*}}$ \\
Ca.Dm $(\boldsymbol{\mu m})$ & $73.01(29.92)$ & $86.27(60.61)^{\mathrm{r}^{\mathrm{0}}}$ & $62.93(19.33)^{\mathrm{n}^{\mathrm{0}}}$ \\
SD Ca.Dm $(\boldsymbol{\mu m})$ & $28.44(13.27)^{\mathrm{n}^{*}}$ & $57.52(24.08)^{\mathrm{d}^{*} \mathrm{r}^{*}}$ & $26.36(12.39)^{\mathrm{n}^{*}}$ \\
${ }^{\mathrm{d}}$ different from femoral diaphysis, ${ }^{\mathrm{n}}$ different from femoral neck, ${ }^{\mathrm{r}}$ different from radial diaphysis \\
${ }^{*} \mathbf{p}<\mathbf{0 . 0 5}$ (Wilcoxon) \\
${ }^{\circ} \mathbf{p}<\mathbf{0 . 0 5}$ (Friedman) \\
\hline
\end{tabular}

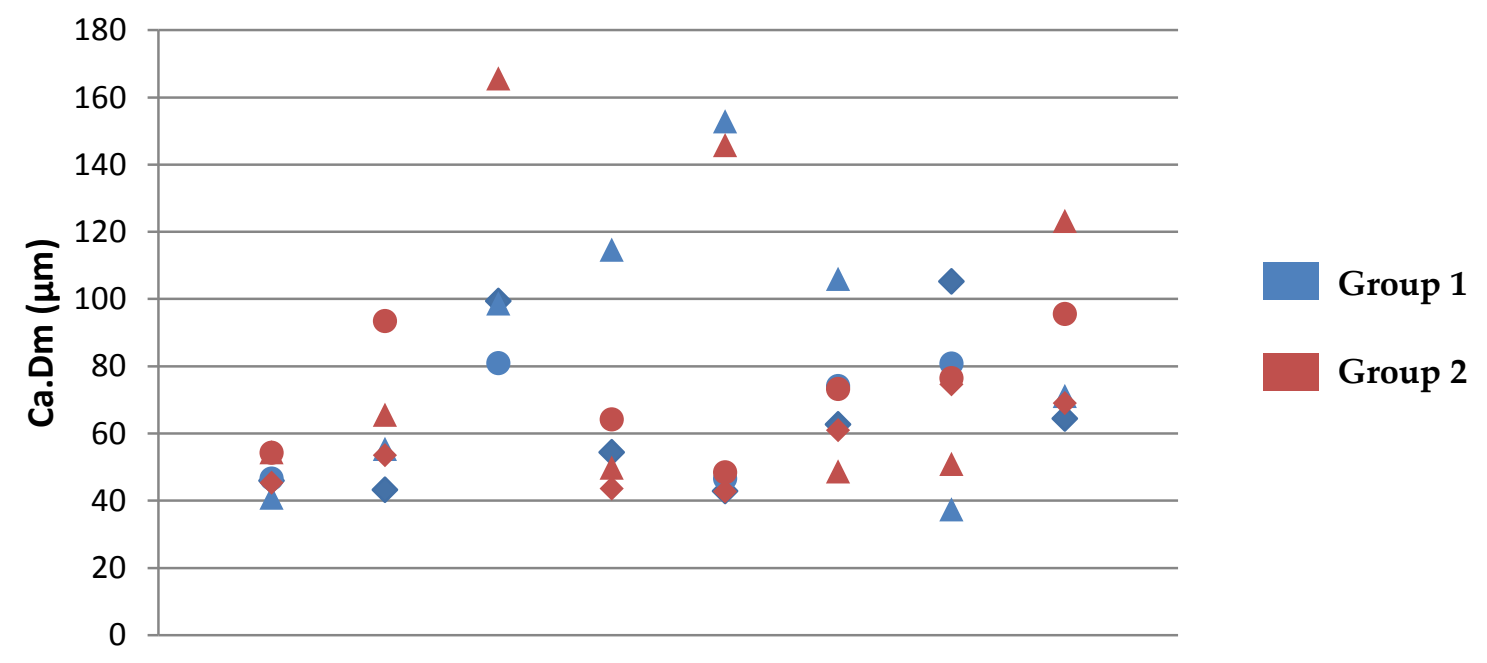

OFemoral diaphysis $\quad \Delta$ Femoral neck $\diamond$ Radial diaphysis

Figure 5 Values of Ca.Dm $(\mu \mathrm{m})$ for each sample. The two contiguous samples are distinguished thanks to the colour chart. 


\subsection{Osteocyte lacunae}

Table 3 and Erreur ! Source du renvoi introuvable. present the mean values over the eight subjects of the lacunae morphometric parameter Lc. $\rho_{1}$. Significant differences between paired anatomical locations are also indicated. It can be noticed that individual geometrical parameters of osteocyte lacunae are significantly different between the radius and the femur (diaphysis and neck). The Lc.L1 at the radius is $18 \%$ larger than in the femoral diaphysis and $16 \%$ higher than in the femoral neck, and the Lc.L2 is $8 \%$ smaller than in the femoral diaphysis and $10 \%$ smaller than in the femoral neck. These differences lead to a sharper shape of lacunae in the radius, with a $27 \%$ and $29 \%$ lower Lc. $\rho_{1}$ and a $19 \%$ and $22 \%$ smaller Lc. $\rho_{2}$ than in the femoral diaphysis and femoral neck, respectively. The average individual lacuna volume and surface, on the other hand, remain the same in all studied anatomical locations. The Lc.N/BV is $18 \%$ lower in the radial diaphysis than in the femoral neck. No significant difference is measured between the locations for the Lc.V/BV.

Table 3 Mean (IQR) values for lacunae morphometric parameters

\begin{tabular}{|c|c|c|c|}
\hline $\begin{array}{c}\text { Morphometric } \\
\text { parameters }\end{array}$ & Femoral diaphysis & Femoral neck & Radial diaphysis \\
\hline Lc.L1 $(\mu \mathrm{m})$ & $21.69(0.97)^{\mathrm{r}^{*}}$ & $22.23(1.76)^{\mathrm{r}^{*}}$ & $25.70(2.19)^{\mathrm{d}^{*} \mathrm{n}^{*}}$ \\
\hline Lc.L2 $(\mu \mathrm{m})$ & $11.71(0.54)^{\mathrm{r}^{*}}$ & $11.99(0.53)^{\mathrm{r}^{*}}$ & $10.81(0.65)^{\mathrm{d}^{*} \mathrm{n}^{*}}$ \\
\hline Lc.L3 ( $\mu \mathrm{m})$ & $5.45(0.59)$ & $5.63(0.33)$ & $5.35(0.28)$ \\
\hline Lc. $\rho_{1}\left(\mu \mathrm{m}^{-1}\right)$ & $6.34(0.60)^{\mathrm{r}^{*}}$ & $6.50(0.78)^{\mathrm{r}^{*}}$ & $4.61(0.78)^{\mathrm{d}^{*} \mathrm{n}^{*}}$ \\
\hline Lc. $\rho_{2}\left(\mu \mathrm{m}^{-1}\right)$ & $1.38(0.28)^{\mathrm{r}^{*}}$ & $1.44(019)^{\mathrm{r} * *}$ & $1.13(0.15)^{\mathrm{d}^{*} \mathrm{n}^{*}}$ \\
\hline Lc.S $\left(\mu \mathbf{m}^{2}\right)$ & $508.71(44.18)$ & $537.36(49.82)$ & $550.50(46.38)$ \\
\hline Lc.V $\left(\mu \mathbf{m}^{3}\right)$ & $561.48(84.81)$ & $571.66(56.20)$ & $589.35(55.58)$ \\
\hline Lc.N/BV $\left(\mathbf{m m}^{-3}\right)$ & $21617.32(3621.85)$ & $26123.55(4990.54)^{\mathrm{r}^{*}}$ & $21191.24(1479.55)^{n^{*}}$ \\
\hline Lc.V/BV (\%) & $1.21(0.21)$ & $1.51(0.32)$ & $1.26(0.12)$ \\
\hline Lc.N & 10028 & 11504 & 9302 \\
\hline $\begin{array}{l}\text { different from femor } \\
p<0.05\end{array}$ & 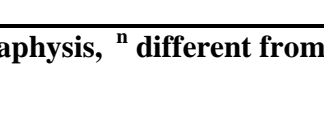 & & al diaphysis \\
\hline
\end{tabular}




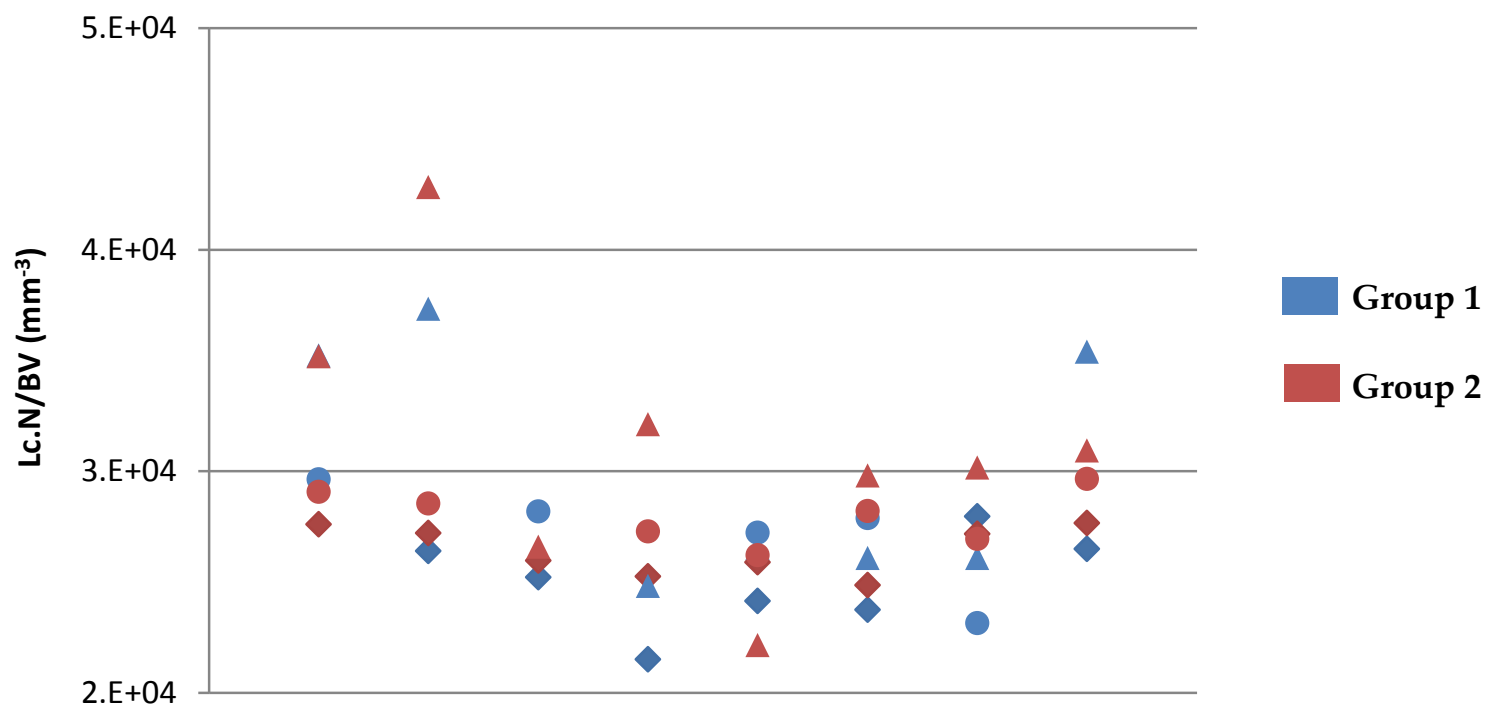

OFemoral diaphysis $\Delta$ Femoral neck $\diamond$ Radial diaphysis

Figure 6 Values of LC.N/BV $\left(\mathrm{mm}^{-3}\right)$ for each sample. The two contiguous samples are distinguished thanks to the colour chart.

\subsection{Micro-cracks}

Table 4 shows the mean values over the 8 subjects for the morphometric parameters of micro-cracks measured in the control VOIs. In contrast to the osteocytes lacunae, micro-cracks appear to have nearly the same morphometric parameters in all three anatomical locations, and no significant difference is measured.

Table 4 Mean (IQR) values for micro-cracks morphometric parameters measured in the VOIs.

\begin{tabular}{|c|c|c|c|}
\hline $\begin{array}{c}\text { Morphometric } \\
\text { parameters }\end{array}$ & Femoral diaphysis & Femoral neck & Radial diaphysis \\
\hline$\mu \mathrm{Cr} . \mathrm{L1}(\boldsymbol{\mu m})$ & $72.94(39.29)$ & $67.12(21.50)$ & $69.69(50.45)$ \\
\hline $\boldsymbol{\mu C r . L 2}(\boldsymbol{\mu m})$ & $28.61(12.70)$ & $30.04(10.01)$ & $30.91(14.50)$ \\
\hline$\mu \mathrm{Cr} . \mathrm{Th}(\boldsymbol{\mu m})$ & $1.92(0.20)$ & $1.99(0.31)$ & $2.06(0.21)$ \\
\hline$\mu \mathrm{Cr} . \mathrm{S}\left(\mu \mathrm{m}^{2}\right)$ & $3181.16(3144.164)$ & $4445.50(3626.99)$ & $5183.01(7347.26)$ \\
\hline$\mu \mathrm{Cr} . \mathrm{V}\left(\mu \mathrm{m}^{3}\right)$ & $2257.43(2197.265)$ & 3735.25 (2886.29) & $4291.97(6242.06)$ \\
\hline$\mu \mathrm{Cr} . \mathrm{V} / \mathrm{BV}\left(\% \times 10^{3}\right)$ & $16.47(9.49)$ & $23.61(19.39)$ & $24.32(17.66)$ \\
\hline
\end{tabular}




\subsection{Relationships between the three anatomical locations}

Table 5 shows the relationships between the three investigated anatomical locations. Regarding the osteonal canals system, no significant correlation has been found between the three anatomical locations. Significant correlations between all of the three locations are observed for Lc. $\rho_{1}$. Others significant relation regarding lacunar parameters can be observed between two different anatomical locations.

Table 5 Spearman's coefficients between the parameters assessed on the three anatomical locations.

\section{Spearman's coefficient}

\begin{tabular}{|c|c|c|c|}
\hline & $\begin{array}{c}\text { Femoral diaphysis / } \\
\text { Femoral neck }\end{array}$ & $\begin{array}{c}\text { Femoral diaphysis / } \\
\text { Radial diaphysis }\end{array}$ & $\begin{array}{l}\text { Femoral neck / } \\
\text { Radial diaphysis }\end{array}$ \\
\hline Ca.V/BV & -0.50 & 0.36 & -0.38 \\
\hline Ca.Dm & -0.07 & 0.64 & -0.05 \\
\hline SD Ca.Dm & -0.60 & 0.60 & -0.41 \\
\hline Lc.L1 & 0.71 & 0.38 & 0.60 \\
\hline Lc.L2 & 0.60 & 0.27 & 0.05 \\
\hline Lc.L3 & 0.31 & 0.24 & $0.76^{*}$ \\
\hline Lc. $\rho_{1}$ & $0.93^{*}$ & $0.95^{*}$ & $0.88^{*}$ \\
\hline Lc. $\rho_{2}$ & 0.64 & 0.71 & $0.88^{*}$ \\
\hline Lc.S & $0.76^{*}$ & 0.00 & 0.05 \\
\hline Lc.V & $0.83^{*}$ & -0.14 & 0.26 \\
\hline Lc.N/BV & 0.62 & 0.17 & 0.50 \\
\hline Lc.V/BV & 0.43 & 0.69 & $0.76^{*}$ \\
\hline p-value $<0.05$ & & & \\
\hline
\end{tabular}

\section{Discussion}

It is known that bone architecture depends on its function within the organism. However, little quantitative information is available concerning the influence of the anatomical locations on cortical bone microstructure. The aim of this study was to measure the morphometric parameters of different types of porosity on eight paired human femoral diaphyses, femoral neck, and radial diaphyses.

With regard to the parameters of the osteonal canals system, the volume fraction of vascular porosity measured on the femoral diaphysis in the current study is in the same order of magnitude as values also measured in 3D found in the literature (Ca.V/TV $=8.45 \pm 2.80 \%$ here, $12.26 \pm 3.15 \%$ in (Perilli et al., 2015), $11.48 \pm 7.0 \%$ in (Wachter et al., 2001), and $7.6 \%$ in (Repp et al., 2017)). Moreover, the 
canal volume fractions measured at the radius in the current study are in the range of results found in the recent study ( $4.34 \pm 2.46$ in the current study, between 2.3 and 13.3 in (Minonzio et al., 2018)). The canal diameter measured in the femoral diaphysis is also in accordance with the data found in the literature $(\mathrm{Ca} . \mathrm{Dm}=73.01 \pm 29.92 \mu \mathrm{m}$ here, $55.09 \pm 14.33 \mu \mathrm{m}$ in (Jowsey, 1966), up to $72 \mu \mathrm{m}$ in (Zimmermann et al., 2011), and 78.24 \pm 43.5 in (Particelli et al., 2012)). It is nevertheless known that canals properties depend on the region investigated within cortical thickness and that the porosity significantly increases close to the endosteum (Bala et al., 2016; Burghardt et al., 2010). In their study, Bala et al., found a large standard deviation for the averaged canals diameter measured on the whole thickness of human fibula reflecting a high variation from the periosteum to the endosteum $(144 \pm 69$ $\mu \mathrm{m}$, (Bala et al., 2016)). Regarding these results and the sample used in the current study, the porosity investigated in the current is representative of an intra-cortical area between the endosteum and periosteum.

The differences in Ca.V/TV found between the femur and the radius could be explained by the nonweight-bearing nature of the radius. Structural differences between weight-bearing and non-weightbearing bones have already been stated in the past (Vico et al., 2000). The internal variation of canal diameter (SD Ca.Dm) was found to be significantly higher in the femoral neck than in the femoral or radial diaphysis. As femoral neck is subjected to a complex mechanical environment (Verhulp et al., 2008), it may be subjected to more remodeling leading to a non-uniform canals network at the time bones were collected. Also, inferior femoral neck cortical thickness is close to $2 \mathrm{~mm}$ (Treece et al., 2010). It is known that the cortical porosity may increase near the transition zone between cortical and trabecular bone (Buenzli et al., 2013). It has also been shown in a previous study that femoral neck is a region of complex osteonal remodeling (Jordan et al., 2000). Different localization of a sample extraction can also occur at the origin of these differences. Samples were extracted from the lateral region of the femoral diaphysis and from the anterior part of the radius. A previous study showed no difference between the osteonal canals diameter measured on the lateral and on the anterior region of the same femoral diaphysis (Carter et al., 2014; Chan et al., 2007). This result suggests that the regional localization of the sample might be minor regarding the results reported in the current study on the canals system.

Considering the lacunar morphometric parameters measured on the femoral diaphysis, values of Lc.L1, Lc.L2 and Lc.L3 demonstrate the same order of magnitude as the values found in the literature (Lc.L1 / Lc.L2 / Lc.L3 = $21.69 \pm 0.97 / 11.71 \pm 0.54$ / $5.45 \pm 0.59 \mu \mathrm{m}$ in the current study, $18.9 \pm 4.9$ / $9.2 \pm 2.1 / 4.8 \pm 1.1 \mu \mathrm{m}$ in (Dong et al., 2014)). The Lc.S and Lc.V values are higher in the current study (Lc.S / Lc.V $=508.71 \pm 44.18 \mu \mathrm{m}^{2} / 561.48 \pm 84.81 \mu \mathrm{m}^{3}$ in the current study, $336.2 \pm 94.5 \mu \mathrm{m}^{2} /$ $409.5 \pm 149.7 \mu \mathrm{m}^{3}$ in (Dong et al., 2014)). The differences found in comparison with the literature may come from the different sizes of the VOI or different voxel sizes (the voxel size used by Dong 
was $1.4 \mu \mathrm{m})$. Moreover, Lc.V measured in the current study is in the same order of magnitude than that found in (Bach-Gansmo et al., 2016) in which analysis was performed on the iliac crest (Lc.V = $561 \pm$ $32 \mu^{3}$ ) for a population older than 57 y.o. The lacunar density is also comparable $(($ Lc.N $/$ BV $)=21617 \pm 3622$ in the current study, $20573 \pm 2850$ in (Dong et al., 2014)). We can see that the lacunar volume fraction is a little overestimated in comparison with the values found in the literature (Lc.V / BV = $1.2 \pm 0.2$ in the current study, $0.9+0.1$ in (Dong et al., 2014)). This slight difference is related to the increased Lc.V in our study. Furthermore, the lacunar density (N.Lc/BV) measured in the current study $\left(\mathrm{Lc} . \mathrm{N} / \mathrm{BV}=21617.32 \pm 3621.85 \mathrm{~mm}^{-3} / 26123.55 \pm 4990.54 \mathrm{~mm}^{-3} /\right.$ $21191.24 \pm 1479.55 \mathrm{~mm}^{-3}$ for femoral diaphysis / femoral neck / radius) is in accordance with the values' range, between 20,000 and 30,000, reported by Buenzli \& Sims, who completed a global review of osteocytes lacunae morphometric parameters over the skeleton (Buenzli and Sims, 2015).

The lacunar geometrical differences between femur and radius might be the consequences of a different nature of the remodeling process related to their different function. Since the femur is a weight-bearing bone and the radius is not, the femur is more often subjected to high levels of loading. This mechanical loading is assumed to be detected by the osteocytes network, which signals initiation of bone turnover (Burr et al., 1985; Lee et al., 2002). It has been shown in the past that the geometry of the lacunae cultured in vitro has an influence on their mechanosensitivity: a flatter lacuna appears to be less mechanosensitive than a rounder lacuna (Bacabac et al., 2008). They explained this difference by pointing out that rounder lacunae have been shown to be less stiff than the flatter ones but also because the area of anchorage of these rounder lacunae cultured in vitro was smaller. Reality may be more complex in vivo, a significant difference in the shape of these lacunae has nevertheless been measured, and this could be an hypothesis. As reported by Carter et al. these differences may also be explained by the different localization used in the current study. Carter et al., found that the lacunae were flatter in the lateral part of the diaphysis than in the anterior region (Carter et al., 2014). If these differences in shape might be explained with difference in the loading applied to the bone during life, it is nevertheless currently difficult to investigate the role of external loading on osteocytes' shape (Maude et al., 2017; Sugawara et al., 2013).

The geometrical parameters of micro-cracks are difficult to compare with the values found in the literature. Several studies were performed using 2D analysis (Diab and Vashishth, 2005; Follet et al., 2013; Vashishth, 2007; Zioupos et al., 2008). For the baseline case, the existing data on three dimensional morphometric parameters of micro-cracks measured on human cortical bone are very limited. Larrue et al. (2011) investigated the geometry of micro-cracks observed on native human trabecular bone (Larrue et al., 2011). Wolfram et al. investigated micro-crack morphology in three dimensions, but only after applying critical loading on human femoral cortical bone samples, which modify the morphology of the micro-cracks (Wolfram et al., 2016). We can compare our results with 
previous $2 \mathrm{D}$ studies. Considering that the main axis of the micro-cracks is the same as measured in previous studies, the values presented in the current study are in accordance with previous results $(\mu \mathrm{Cr} . \mathrm{L} 1=72.94 \pm 39.29 \mu \mathrm{m}$ in the current study, $75 \pm 26 \mu \mathrm{m}$ in (Sobelman et al., 2004), $72.6 \pm 13 \mu \mathrm{m}$ in (Haupert et al., 2014)). We also notice that, in the current study, $\mu$ Cr.L2 ranged between $13 \mu \mathrm{m}$ and $91 \mu \mathrm{m}$ over the eight subjects on the femoral diaphysis.

It is interesting to note that there are no differences in the geometrical parameters of micro-cracks between the different anatomical locations. This might indicate that the accumulation of micro-cracks proceeds similarly in all three studied sites. However, it might also be due to the fact that the bone tissue reacts in a similar way between the sites during sample preparation in terms of defect geometry. Future studies to analyze the effect of the sample preparation protocol on micro-crack morphometric parameters are thus necessary, such as the investigation of different preparation protocol on crack morphology.

The current study presents some limitations. First, the micro-cracks were quantified by considering an ellipsoid fit, which might not accurately relay their actual geometrical parameters. Micro-cracks can undergo some deviation, which may increase their geodesic length but not the length of the best-fitting ellipsoid. However the parameters assessed in the current study are not affected by this method of analysis. Future work could be done in order to improve the investigation of these micro-cracks. Furthermore, the sample preparation method might have introduced micro-defects post-hoc. The amount of micro-cracks observed in our samples might not be representative of bone tissue in vivo.

The size of the VOIs used in the current study might be a limitation, since it is small compared to other studies found in the literature (Dong et al., 2014; Hannah et al., 2010; Haupert et al., 2014; Sobelman et al., 2004). Due to the large number of volumes (48), we had to reduce the size of the analyzed region to avoid an excessively long processing time. Moreover, to consider the internal variability within the same bone, two samples were investigated on each location, implying a real analyzed volume being multiplied by two. Results showed no significant variation within a same anatomical location with consideration for the volumes used in the current study, except for the heterogeneity in canal diameters as measured in the femoral neck (SD Ca.Dm).

Then, our population involved only eight female subjects (aged 50 to 91 y.o.). It is known that the porosity network is dependent of the age and sex of the subject (Bala et al., 2012; Vashishth et al., 2005). In the current study, no correlation was found between age and any measured morphometric parameters, probably due to the limited age range. We note, however, that the samples used are representative of a population of post-menopausal women.

To our knowledge, this is the first study investigating the multi-scale pore network of paired human femoral diaphysis and neck and radial diaphysis using SR- $\mu \mathrm{CT}$ with a voxel size of $0.7 \mu \mathrm{m}$. It is 
known femoral diaphysis, femoral neck, and radial diaphysis demonstrate different fracture behavior under a standard condition of loading (Gauthier et al., 2017). The microstructural difference observed in the current study may be at the origin of this variation of mechanical behavior from an anatomical location to another, as it is known that porosity can have an influence on cortical bone fracture toughness (Ural, 2007).

\section{Conclusion}

In the current study, we assessed the morphometric parameters of human cortical bone on eight paired femoral diaphyses, femoral necks, and radial diaphyses. Results show that the vascular canals are wider in the femoral diaphysis or neck than in the radius. The femoral neck appears to have a more heterogeneous osteonal canals system, and lacunae observed in the radial diaphysis are longer and sharper. The amount of lacunae within the femoral neck is significantly higher than in the femoral or radial diaphysis. These results provide evidence that the internal organization of the tissue depends on the weight-bearing or non-weight-bearing nature of the bone. In future work, analysis of the osteons should be of interest, since they are considered to be the basic bone mechanical units. On a lower scale, understanding the role of the canaliculi may also be of great interest.

\section{Acknowledgments}

The authors acknowledge the ESRF ID19 staff for his support for synchrotron data acquisition during the experiment MD923. This work was supported by the LabEx PRIMES (ANR-11-LABX-0063) within the program "Investissements d'Avenir" (ANR-11-IDEX-0007). This study was also partly funded by the Région Auvergne-Rhône-Alpes (14-011125-01) and by the ANR project MUTLIPS (ANR-13-BS09-0006). The authors also want to thank the Fédération INGE'LYSE for its financial support.

\section{Bibliography}

Bacabac, R.G., Mizuno, D., Schmidt, C.F., MacKintosh, F.C., Van Loon, J.J.W.A., Klein-Nulend, J., Smit, T.H., 2008. Round versus flat: Bone cell morphology, elasticity, and mechanosensing. J. Biomech. 41, 1590-1598. doi:10.1016/j.jbiomech.2008.01.031

Bach-Gansmo, F.L., Brüel, A., Jensen, M.V., Ebbesen, E.N., Birkedal, H., Thomsen, J.S., 2016. Osteocyte lacunar properties and cortical microstructure in human iliac crest as a function of age and sex. Bone 91, 11-19. doi:10.1016/j.bone.2016.07.003

Bala, Y., Depalle, B., Farlay, D., Douillard, T., Meille, S., Follet, H., Chapurlat, R., Chevalier, J., Boivin, G., 2012. Bone micromechanical properties are compromised during long-term alendronate therapy independently of mineralization. J. Bone Miner. Res. 27, 825-834. doi:10.1002/jbmr.1501

Bala, Y., Lefevre, E., Roux, J.P., Baron, C., Lasaygues, P., Pithioux, M., Kaftandjian, V., Follet, H., 
2016. Pore network microarchitecture influences human cortical bone elasticity during growth and aging. J. Mech. Behav. Biomed. Mater. 63, 164-173. doi:10.1016/j.jmbbm.2016.05.018

Bell, K.L., Loveridge, N., Power, J., Garrahan, N., Stanton, M., Lunt, M., Meggitt, B.F., Reeve, J., 1999. Structure of the femoral neck in hip fracture: cortical bone loss in the inferoanterior to superoposterior axis. J. Bone Miner. Res. 14, 111-119. doi:10.1359/jbmr.1999.14.1.111

Betts, D.C., Goff, E., Casanova, M., Li, Z., P., C., Müller, R., 2017. Osteocyte lacuna segmentation from ultr-high resolution desktop micro-CT images: Low precision reveals limitation of state of the art, in: International Bone Densitometry Workshop.

Bonewald, L.F., 2011. The amazing osteocyte. J. Bone Miner. Res. 26, 229-238. doi:10.1002/jbmr.320

Bousson, V., Peyrin, F., Bergot, C., Hausard, M., Sautet, A., Laredo, J.-D., 2004. Cortical bone in the human femoral neck: three-dimensional appearance and porosity using synchrotron radiation. J. Bone Miner. Res. 19, 794-801. doi:10.1359/JBMR.040124

Buenzli, P.R., Sims, N. a., 2015. Quantifying the osteocyte network in the human skeleton. Bone 75, 144-150. doi:10.1016/j.bone.2015.02.016

Buenzli, P.R., Thomas, C.D.L., Clement, J.G., Pivonka, P., 2013. Endocortical bone loss in osteoporosis: The role of bone surface availability. Int. j. numer. method. biomed. eng. 29, 13071322. doi:10.1002/cnm.2567

Burghardt, A.J., Kazakia, G.J., Ramachandran, S., Link, T.M., Majumdar, S., 2010. Age- and genderrelated differences in the geometric properties and biomechanical significance of intracortical porosity in the distal radius and tibia. J. Bone Miner. Res. 25, 983-993. doi:10.1359/jbmr.091104

Burr, D.B., 2001. Microdamage and bone fragility. Curr. Opin. Orthop. 12, 365-370. doi:10.1097/00001433-200110000-00001

Burr, D.B., Forwood, M.R., Fyhrie, D.P., Martin, R.B., Schaffler, M.B., Turner, C.H., 1997. Bone Microdamage and Skeletal Fragility in Osteoporotic and Stress Fractures. J. Bone Miner. Res. 12, 6-15. doi:10.1359/jbmr.1997.12.1.6

Burr, D.B., Martin, R.B., Schaffler, M.B., Radin, E.L., 1985. Bone remodeling in response to in vivo fatigue microdamage. J. Biomech. 18, 189-200. doi:10.1016/0021-9290(85)90204-0

Busse, B., Djonic, D., Milovanovic, P., Hahn, M., Püschel, K., Ritchie, R.O., Djuric, M., Amling, M., 2010. Decrease in the osteocyte lacunar density accompanied by hypermineralized lacunar occlusion reveals failure and delay of remodeling in aged human bone. Aging Cell 9, 1065-1075. doi:10.1111/j.1474-9726.2010.00633.x

Carter, Y., Suchorab, J.L., Thomas, C.D.L., Clement, J.G., Cooper, D.M.L., 2014. Normal variation in cortical osteocyte lacunar parameters in healthy young males. J. Anat. 225, 328-336. doi:10.1111/joa.12213

Chan, A.H.W., Crowder, C.M., Rogers, T.L., 2007. Variation in cortical bone histology within the human femur and its impact on estimating age at death. Am. J. Phys. Anthropol. 132, 80-88. 
doi:10.1002/ajpa.20465

Chappard, C., Basillais, A., Benhamou, L., Bonassie, A., Brunet-Imbault, B., Bonnet, N., Peyrin, F., 2006. Comparison of synchrotron radiation and conventional $\mathrm{x}$-ray microcomputed tomography for assessing trabecular bone microarchitecture of human femoral heads. Med. Phys. 33, 35683577. doi:10.1118/1.2256069

Cooper, D.M.L., Thomas, C.D.L., Clement, J.G., Turinsky, A.L., Sensen, C.W., Hallgrímsson, B., 2007. Age-dependent change in the 3D structure of cortical porosity at the human femoral midshaft. Bone 40, 957-965. doi:10.1016/j.bone.2006.11.011

Currey, J.D., Shahar, R., 2013. Cavities in the compact bone in tetrapods and fish and their effect on mechanical properties. J. Struct. Biol. 183, 107-122. doi:10.1016/j.jsb.2013.04.012

Di Zenzo, S., Cinque, L., Levialdi, S., 1996. Run-based algorithms for binary image analysis and processing. IEEE Trans. Pattern Anal. Mach. Intell. 18, 83-89. doi:10.1109/34.476016

Diab, T., Vashishth, D., 2005. Effects of damage morphology on cortical bone fragility. Bone 37, 96102. doi:10.1016/j.bone.2005.03.014

Dong, P., Haupert, S., Hesse, B., Langer, M., Gouttenoire, P.J., Bousson, V., Peyrin, F., 2014. 3D osteocyte lacunar morphometric properties and distributions in human femoral cortical bone using synchrotron radiation micro-CT images. Bone 60, 172-185. doi:10.1016/j.bone.2013.12.008

Follet, H., Farlay, D., Bala, Y., Viguet-Carrin, S., Gineyts, E., Burt-Pichat, B., Wegrzyn, J., Delmas, P., Boivin, G., Chapurlat, R., 2013. Determinants of Microdamage in Elderly Human Vertebral Trabecular Bone. PLoS One 8. doi:10.1371/journal.pone.0055232

Gauthier, R., Follet, H., Langer, M., Meille, S., Chevalier, J., Rongiéras, F., Peyrin, F., Mitton, D., 2017. Strain rate influence on human cortical bone toughness: A comparative study of four paired anatomical sites. J. Mech. Behav. Biomed. Mater. 71, 223-230. doi:10.1016/j.jmbbm.2017.03.015

Gourion-Arsiquaud, S., Burket, J.C., Havill, L.M., DiCarlo, E., Doty, S.B., Mendelsohn, R., Van Der Meulen, M.C.H., Boskey, A.L., 2009. Spatial variation in osteonal bone properties relative to tissue and animal age. J. Bone Miner. Res. 24, 1271-1281. doi:10.1359/jbmr.090201

Granke, M., Makowski, A.J., Uppuganti, S., Nyman, J.S., 2016. Prevalent role of porosity and osteonal area over mineralization heterogeneity in the fracture toughness of human cortical bone. J. Biomech. 49, 2748-2755. doi:10.1016/j.jbiomech.2016.06.009

Hannah, K.M., Thomas, C.D.L., Clement, J.G., De Carlo, F., Peele, A.G., 2010. Bimodal distribution of osteocyte lacunar size in the human femoral cortex as revealed by micro-CT. Bone $47,866-$ 871. doi:10.1016/j.bone.2010.07.025

Haupert, S., Guérard, S., Peyrin, F., Mitton, D., Laugier, P., 2014. Non destructive characterization of cortical bone micro-damage by nonlinear resonant ultrasound spectroscopy. PLoS One 9. doi:10.1371/journal.pone.0083599 
Hennig, C., Thomas, C.D.L., Clement, J.G., Cooper, D.M.L., 2015. Does 3D orientation account for variation in osteon morphology assessed by 2D histology? J. Anat. 227, 497-505. doi:10.1111/joa.12357

Heřt, J., Fiala, P., Petrtýl, M., 1994. Osteon orientation of the diaphysis of the long bones in man. Bone 15, 269-277. doi:10.1016/8756-3282(94)90288-7

Hildebrand, T., Rüegsegger, P., 1997. Quantification of Bone Microarchitecture with the Structure Model Index. Comput. Methods Biomech. Biomed. Engin. 1, 15-23. doi:10.1080/01495739708936692

Jordan, G.R., Loveridge, N., Bell, K.L., Power, J., Rushton, N., Reeve, J., 2000. Spatial clustering of remodeling osteons in the femoral neck cortex: A cause of weakness in hip fracture? Bone 26, 305-313. doi:10.1016/S8756-3282(99)00272-0

Jowsey, J., 1966. Studies of Haversian systems in man and some animals. J. Anat. 100, 857-64. doi:10.1002/ajpa

Jowsey, J., Owen, M., Vaughan, J., 1953. Microradiographs and autoradiographs of cortical bone from monkeys injected with 90Sr. Br. J. Exp. Pathol. 34, 661-7.

Lai, X., Price, C., Modla, S., Thompson, W.R., Caplan, J., Kirn-Safran, C.B., Wang, L., 2015. The dependences of osteocyte network on bone compartment, age, and disease. Bone Res. 3, 15009. doi:10.1038/boneres.2015.9

Langer, M., Pacureanu, A., Suhonen, H., Grimal, Q., Cloetens, P., Peyrin, F., 2012. X-Ray Phase Nanotomography Resolves the 3D Human Bone Ultrastructure. PLoS One 7. doi:10.1371/journal.pone.0035691

Larrue, A., Rattner, A., Peter, Z.A., Olivier, C., Laroche, N., Vico, L., Peyrin, F., 2011. Synchrotron radiation micro-CT at the Micrometer scale for the analysis of the three-dimensional morphology of microcracks in human trabecular bone. PLoS One 6, e21297. doi:10.1371/journal.pone.0021297

Lee, T.C., Staines, a., Taylor, D., 2002. Bone adaptation to load: Microdamage as a stimulus for bone remodelling. J. Anat. 201, 437-446. doi:10.1046/j.1469-7580.2002.00123.x

Marotti, G., 1979. Osteocyte orientation in human lamellar bone and its relevance to the morphometry of periosteocytic lacunae. Metab. Bone Dis. Relat. Res. 1, 325-333. doi:10.1016/02218747(79)90027-4

Martín-Badosa, E., Elmoutaouakkil, A., Nuzzo, S., Amblard, D., Vico, L., Peyrin, F., 2003. A method for the automatic characterization of bone architecture in 3D mice microtomographic images. Comput. Med. Imaging Graph. 27, 447-458. doi:10.1016/S0895-6111(03)00031-4

Maude, G., Vasily, G., Delphine, F., Cécile, O., Patrick, A., Guillaume, C., Norbert, L., Rachel, G., Hélène, F., Françoise, P., Boris, S., Guillemette, G.K., Laurence, V., 2017. One-month spaceflight compromises the bone microstructure, tissue-level mechanical properties, osteocyte survival and lacunae volume in mature mice skeletons. Sci. Rep. 7, 41598. doi:10.1038/s41598- 
017-03014-2

Mikkola, T.M., Sipilä, S., Rantanen, T., Sievänen, H., Suominen, H., Kaprio, J., Koskenvuo, M., Kauppinen, M., Heinonen, A., 2008. Genetic and environmental influence on structural strength of weight-bearing and non-weight-bearing bone: A twin study. J. Bone Miner. Res. 23, 492-498. doi:10.1359/jbmr.071205

Milovanovic, P., Zimmermann, E.A., Riedel, C., Scheidt, A. Vom, Herzog, L., Krause, M., Djonic, D., Djuric, M., Püschel, K., Amling, M., Ritchie, R.O., Busse, B., 2015. Multi-level characterization of human femoral cortices and their underlying osteocyte network reveal trends in quality of young, aged, osteoporotic and antiresorptive-treated bone. Biomaterials 45, 46-55. doi:10.1016/j.biomaterials.2014.12.024

Minonzio, J.-G., Bochud, N., Vallet, Q., Bala, Y., Ramiandrisoa, D., Follet, H., Mitton, D., Laugier, P., 2018. Bone cortical thickness and porosity assessment using ultrasound guided waves: An ex vivo validation study. Bone \#pagerange\#. doi:10.1016/j.bone.2018.07.018

Nalla, R.K., Kruzic, J.J., Kinney, J.H., Balooch, M., Ager, J.W., Ritchie, R.O., 2006. Role of microstructure in the aging-related deterioration of the toughness of human cortical bone. Mater. Sci. Eng. C 26, 1251-1260. doi:10.1016/j.msec.2005.08.021

Pacureanu, A., Langer, M., Boller, E., Tafforeau, P., Peyrin, F., 2012. Nanoscale imaging of the bone cell network with synchrotron X-ray tomography: optimization of acquisition setup. Med. Phys. 39, 2229. doi:10.1118/1.3697525

Paganin, D., Mayo, S.C., Gureyev, T.E., Miller, P.R., Wilkins, S.W., 2002. Simultaneous phase and amplitude extraction from a single defocused image of a homogeneous object. J. Microsc. 206, 33-40. doi:10.1046/j.1365-2818.2002.01010.x

Paleo, P., Mirone, A., 2017. Efficient implementation of a local tomography reconstruction algorithm. Adv. Struct. Chem. Imaging 3, 5. doi:10.1186/s40679-017-0038-1

Particelli, F., Mecozzi, L., Beraudi, A., Montesi, M., Baruffaldi, F., Viceconti, M., 2012. A comparison between micro-CT and histology for the evaluation of cortical bone: Effect of polymethylmethacrylate embedding on structural parameters. J. Microsc. 245, 302-310. doi:10.1111/j.1365-2818.2011.03573.x

Perilli, E., Bala, Y., Zebaze, R., Reynolds, K.J., Seeman, E., 2015. Regional Heterogeneity in the Configuration of the Intracortical Canals of the Femoral Shaft. Calcif. Tissue Int. doi:10.1007/s00223-015-0014-5

Pfeiffer, S., Crowder, C., Harrington, L., Brown, M., 2006. Secondary osteon and Haversian canal dimensions as behavioral indicators. Am. J. Phys. Anthropol. 131, 460-468. doi:10.1002/ajpa.20454

Repp, F., Kollmannsberger, P., Roschger, A., Kerschnitzki, M., Berzlanovich, A., Gruber, G., Roschger, P., Wagermaier, W., Weinkamer, R., 2017. Spatial heterogeneity in the canalicular density of the osteocyte network in human osteons. Bone Reports 6, 101-108. 
doi:10.1016/j.bonr.2017.03.001

Salomé, M., Peyrin, F., Cloetens, P., Odet, C., Laval-Jeantet, a M., Baruchel, J., Spanne, P., 1999. A synchrotron radiation microtomography system for the analysis of trabecular bone samples. Med. Phys. 26, 2194-2204. doi:10.1118/1.598736

Schladitz, K., Ohser, J., Nagel, W., 2006. Measuring Intrinsic Volumes in Digital 3d Images. Discret. Geom. Comput. Imag. 4245, 247-258. doi:10.1007/11907350_21

Schneider, P., Meier, M., Wepf, R., Müller, R., 2011. Serial FIB/SEM imaging for quantitative 3D assessment of the osteocyte lacuno-canalicular network. Bone 49, 304-311. doi:10.1016/j.bone.2011.04.005

Seeman, E., Delmas, P.D., 2006. Bone quality--the material and structural basis of bone strength and fragility. N. Engl. J. Med. 354, 2250-2261. doi:10.1056/NEJMra053077

Sobelman, O.S., Gibeling, J.C., Stover, S.M., Hazelwood, S.J., Yeh, O.C., Shelton, D.R., Martin, R.B., 2004. Do microcracks decrease or increase fatigue resistance in cortical bone? J. Biomech. 37, 1295-1303. doi:10.1016/j.jbiomech.2003.12.034

Sugawara, Y., Kamioka, H., Ishihara, Y., Fujisawa, N., Kawanabe, N., Yamashiro, T., 2013. The early mouse 3D osteocyte network in the presence and absence of mechanical loading. Bone 52, 189196. doi:10.1016/j.bone.2012.09.033

Treece, G.M., Gee, a. H., Mayhew, P.M., Poole, K.E.S., 2010. High resolution cortical bone thickness measurement from clinical CT data. Med. Image Anal. 14, 276-290. doi:10.1016/j.media.2010.01.003

Ural, A., 2007. Effects of Intracortical Porosity on Fracture Toughness in Aging Human Bone: A microCT Based Cohesive Finite Element Study. J. Biomech. Eng. 129, 625. doi:10.1115/1.2768377

Vallet, Q., Bochud, N., Chappard, C., Laugier, P., Minonzio, J.-G., 2016. In Vivo Characterization of Cortical Bone Using Guided Waves Measured by Axial Transmission. IEEE Trans. Ultrason. Ferroelectr. Freq. Control 63, 1361-1371. doi:10.1109/TUFFC.2016.2587079

van Hove, R.P., Nolte, P.A., Vatsa, A., Semeins, C.M., Salmon, P.L., Smit, T.H., Klein-Nulend, J., 2009. Osteocyte morphology in human tibiae of different bone pathologies with different bone mineral density - Is there a role for mechanosensing? Bone 45, 321-329. doi:10.1016/j.bone.2009.04.238

van Oers, R.F.M., Ruimerman, R., Tanck, E., Hilbers, P.A.J., Huiskes, R., 2008. A unified theory for osteonal and hemi-osteonal remodeling. Bone 42, 250-259. doi:10.1016/j.bone.2007.10.009

Varga, P., Hesse, B., Langer, M., Schrof, S., Männicke, N., Suhonen, H., Pacureanu, A., Pahr, D., Peyrin, F., Raum, K., 2014. Synchrotron X-ray phase nano-tomography-based analysis of the lacunar-canalicular network morphology and its relation to the strains experienced by osteocytes in situ as predicted by case-specific finite element analysis. Biomech. Model. Mechanobiol. doi:10.1007/s10237-014-0601-9 
Vashishth, D., 2007. Hierarchy of bone microdamage at multiple length scales. Int. J. Fatigue 29, 1024-1033. doi:10.1016/j.ijfatigue.2006.09.010

Vashishth, D., Gibson, G.J., Fyhrie, D.P., 2005. Sexual dimorphism and age dependence of osteocyte lacunar density for human vertebral cancellous bone. Anat. Rec. - Part A Discov. Mol. Cell. Evol. Biol. 282, 157-162. doi:10.1002/ar.a.20146

Vatsa, A., Breuls, R.G., Semeins, C.M., Salmon, P.L., Smit, T.H., Klein-Nulend, J., 2008. Osteocyte morphology in fibula and calvaria - Is there a role for mechanosensing? Bone 43, 452-458. doi:10.1016/j.bone.2008.01.030

Verbruggen, S.W., Vaughan, T.J., McNamara, L.M., 2012. Strain amplification in bone mechanobiology: a computational investigation of the in vivo mechanics of osteocytes. J. R. Soc. Interface 9, 2735-2744. doi:10.1098/rsif.2012.0286

Verhulp, E., van Rietbergen, B., Huiskes, R., 2008. Load distribution in the healthy and osteoporotic human proximal femur during a fall to the side. Bone 42, 30-35. doi:10.1016/j.bone.2007.08.039

Vico, L., Collet, P., Guignandon, A., Lafage-Proust, M.H., Thomas, T., Rehailia, M., Alexandre, C., 2000. Effects of long-term microgravity exposure on cancellous and cortical weight-bearing bones of cosmonauts. Lancet 355, 1607-1611. doi:10.1016/S0140-6736(00)02217-0

Wachter, N.J., Augat, P., Krischak, G.D., Mentzel, M., Kinzl, L., Claes, L., 2001. Prediction of cortical bone porosity in vitro by microcomputed tomography. Calcif. Tissue Int. 68, 38-42. doi:10.1007/s002230001182

Wang, L., Wang, Y., Han, Y., Henderson, S.C., Majeska, R.J., Weinbaum, S., Schaffler, M.B., 2005. In situ measurement of solute transport in the bone lacunar-canalicular system. Proc. Natl. Acad. Sci. U. S. A. 102, 11911-11916. doi:10.1073/pnas.0505193102

Wolfram, U., Schwiedrzik, J.J., Mirzaali, M.J., Bürki, A., Varga, P., Olivier, C., Peyrin, F., Zysset, P.K., 2016. Characterizing microcrack orientation distribution functions in osteonal bone samples. J. Microsc. 00, 1-14. doi:10.1111/jmi.12440

Zebaze, R., Ghasem-Zadeh, A., Bohte, A., Iuliano-Burns, S., Mirams, M., Price, R.I., Mackie, E.J., Seeman, E., 2010. Intracortical remodelling and porosity in the distal radius and post-mortem femurs of women: a cross-sectional study. Lancet 375, 1729-1736. doi:10.1016/S01406736(10)60320-0

Zimmermann, E.A., Ritchie, R.O., 2015. Bone as a Structural Material. Adv. Healthc. Mater. 4, 12871304. doi:10.1002/adhm. 201500070

Zimmermann, E.A., Schaible, E., Bale, H., Barth, H.D., Tang, S.Y., Reichert, P., Busse, B., Alliston, T., Ager, J.W., Ritchie, R.O., 2011. Age-related changes in the plasticity and toughness of human cortical bone at multiple length scales. Proc. Natl. Acad. Sci. 108, 14416-14421. doi:10.1073/pnas.1107966108

Zioupos, P., Hansen, U., Currey, J.D., 2008. Microcracking damage and the fracture process in relation to strain rate in human cortical bone tensile failure. J. Biomech. 41, 2932-2939. 
doi:10.1016/j.jbiomech.2008.07.025 